\title{
EQ COATING: A NEW CONCEPT FOR SRZ-FREE COATING SYSTEMS
}

\author{
Kyoko Kawagishi ${ }^{1}$, Hiroshi Harada ${ }^{1}$, Akihiro Sato ${ }^{1,2}$, Kazuhide Matsumoto ${ }^{1}$ \\ ${ }^{1}$ National Institute for Materials Science, 1-2-1 Sengen, Tsukuba, Ibaraki, 305-0047, Japan \\ ${ }^{2}$ Present Address: IHI Corporation, 1 Shin-Nakahara-cho, Isogo-ku, Yokohama 235-8501, Japan
}

Keywords: EQ coating, SRZ, Interdiffusion, Equilibrium, Oxidation resistance

\begin{abstract}
Ni-base single crystal (SC) superalloys with high concentrations of refractory elements prone to generate a diffusion layer called Secondary Reaction Zone (SRZ) beneath their bond coating during long time exposure at high temperatures. SRZ causes a reduction of the load bearing cross section and it is detrimental to the creep properties of thin-wall turbine airfoils. In this study, a new bond coat system, "EQ coating" which is thermodynamically stable and suppresses SRZ has been proposed. Diffusion couples of coating materials and substrate alloys were made and were heat treated at $1100^{\circ} \mathrm{C}$ for $300 \mathrm{~h}$ and $1000 \mathrm{~h}$. Cyclic oxidation examinations were carried out at $1100^{\circ} \mathrm{C}$ in air and the oxidation properties of EQ coating materials were discussed. High velocity frame sprayed (HVOF) EQ coatings designed for $2^{\text {nd }}$ generation $\mathrm{Ni}$-base superalloy were deposited on $4^{\text {th }}$ generation Ni-base superalloys. The stability of microstructure at the interface and creep property of the coating system were investigated. Less than $50 \mu \mathrm{m}$-thick of the interdiffusion zone and no SRZ were observed in EQ coating system after $300 \mathrm{~h}$ heat treatment at $1100^{\circ} \mathrm{C}$, in contrast to beyond $90 \mu \mathrm{m}$-thick of diffusion zone and $140 \mu \mathrm{m}$-thick of SRZ in the conventional CoNiCrAlY coating system. Creep strength of Al-diffusion and CoNiCrAlY coated $4^{\text {th }}$ generation superalloys showed decrease in thin creep specimens, but EQ coated $4^{\text {th }}$ generation superalloy showed equivalent creep strength for bare material.
\end{abstract}

\section{Introduction}

Ni-base superalloys which have excellent high-temperature strength and oxidation resistance are required for high output and high efficiency of gas turbines and jet engines. Advanced generation Ni-base superalloys, which contain large amount of strengthening elements and platinum-group metals, realize excellent high-temperature strength and suppression of TCP phase formation $[1,2]$. However, these alloys are required to be applied with oxidation-resistant coating on the surface for the practical use because they are likely to have lower oxidation resistance than the previous generations of superalloys due to the nature of the alloying elements.

Applying the conventional coatings such as Pt-Al or MCrAlY to Re containing advanced generation single-crystal superalloys, a harmful layer so called secondary reaction zone (SRZ) is formed at the interface of coating and substrate [3-5] due to the interdiffusion during the high temperature exposure and the oxidation resistance of the coating layer and the mechanical properties of the substrates result in degradation [6]. Various techniques such as "diffusion barrier" [4, 7-9] and "carburization" [5] have been employed to minimize interdiffusion between the bond coat and the substrate, but these techniques still have some problems in complicated manufacturing process and long-time exposure in high-temperature.

A new concept of coating system, "EQ coating" has been proposed in our previous research [10-14]. In this system, stable phases in thermodynamically equilibrium with substrate such as $\gamma$ ' phase are used as coating materials, and SRZ formation between the coating and the substrate is suppressed. Interdiffusion is minimized because chemical potentials of alloying elements in the substrate and coating in equilibrium state are equal to each other. EQ coating is very fantastic technique stabilizing the microstructure of bond coat/substrate interface. The oxidation resistance of $\gamma^{\prime}$ is the best in the $\gamma / \gamma^{\prime}$ tie-line compositions which are in equilibrium with the substrate superalloy [11], so we suggest using $\gamma^{\prime}$ phase as the EQ coating. However, depending on the substrate superalloys, the oxidation resistance of $\gamma^{\prime}$ phases are inferior to the conventional MCrAlY coating. Usually, $\beta$ phase has superior oxidation property to $\gamma^{\prime}$ phase and it is possible to use $\beta$ phase as EQ coating $[13,14]$ with superalloys which are in equilibrium with $\beta$ phase. Thus, improvement the oxidation property of $\gamma^{\prime}$ EQ coating for the advanced Ni-base superalloy is required. In this study, the compositions of $\gamma^{\prime}$ phase of Ni-base superalloys are modified to improve the oxidation resistance and the SRZ formation at the interface caused by the composition adjustment is investigated. Optimal composition of EQ coating for the advanced superalloys is found for the practical use.

\section{$y / \gamma^{\prime}$ Phase EQ Coating}

Conventional Ni-base superalloys consist of regularly-arranged $\gamma$ phase and $\gamma^{\prime}$ phase. These two phases are in thermodynamical equilibrium, and so chemical potential $\mu_{i}$ of alloying elements $i$ $(i=\mathrm{Ni}, \mathrm{Al}$, etc...) in each phase are equal, and expressed as following equation.

$$
\mu_{i}^{\gamma}=\mu_{i}^{\gamma^{\prime}}
$$

$\gamma$ phase and $\gamma^{\prime}$ phase alloys and $\gamma / \gamma^{\prime}$ tie-line alloys which have completely same composition as $\gamma$ phase and $\gamma^{\prime}$ phase of Ni-base superalloy substrate are able to be used as EQ coating material. Figure 1 shows $(\mathrm{Ni}, \mathrm{X})-(\mathrm{Al}, \mathrm{Y})$ pseudo-binary phase diagram. Substrate $\mathrm{S}$ on a broken line, which means $\gamma / \gamma^{\prime}$ tie-line, consists of $\gamma$ phase of composition A and $\gamma^{\prime}$ phase of composition B. Concentration of alloying element $i$ in alloy $\mathrm{C}$ on the tie-line is expressed as

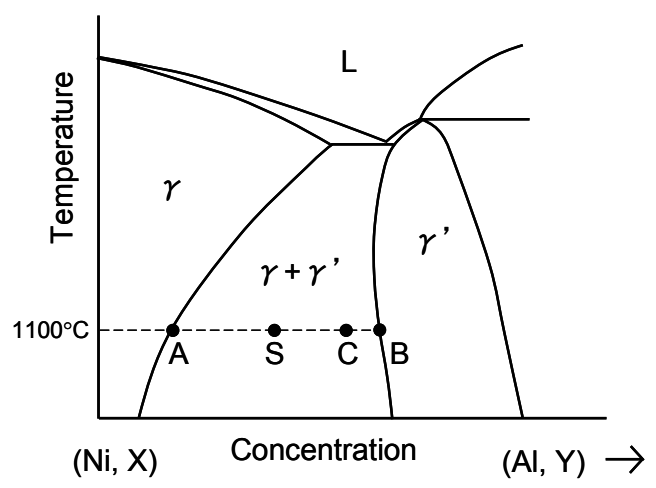

Figure 1. (Ni, X)-(Al, Y) pseudo-binary phase diagram. 
Table I. Nominal Compositions of Substrates and Coatings. (wt\%, Ni bal.)

\begin{tabular}{|rl|rrrrrrrrrr|}
\hline \multicolumn{2}{|c|}{ Sample } & Co & Cr & Mo & W & Al & Ti & Ta & Hf & Re & $\mathrm{Ru}$ \\
\hline \multirow{2}{*}{ TMS82+ } & substrate & 7.7 & 4.6 & 1.8 & 8.6 & 5.3 & 0.5 & 6.3 & 0.1 & 2.4 & - \\
& $\gamma$ & 10.5 & 7.6 & 2.6 & 10.0 & 2.9 & 0.2 & 3.4 & 0.0 & 4.2 & - \\
& $\gamma^{\prime}$ & 4.7 & 1.4 & 0.9 & 7.2 & 7.9 & 0.7 & 9.5 & 0.2 & 0.5 & - \\
\hline \multirow{2}{*}{ TMS-173 } & substrate & 5.6 & 3.0 & 2.8 & 5.6 & 5.6 & - & 5.6 & 0.1 & 6.9 & 5.0 \\
& $\gamma^{\prime}$ & 4.2 & 1.5 & 1.5 & 5.3 & 7.8 & - & 8.0 & 0.2 & 2.6 & 3.9 \\
\hline \multirow{2}{*}{ TMS-209 } & substrate & 8.7 & 10.6 & 2.2 & 4.4 & 6.2 & - & 8.5 & 0.2 & - & - \\
& $\beta$ & 7.3 & 7.9 & 1.1 & 0.1 & 17.4 & - & 1.3 & 0.1 & - & - \\
\hline
\end{tabular}

$$
c_{i}^{\mathrm{C}}=(1-f) c_{i}^{\mathrm{A}}+f c_{i}^{\mathrm{B}},
$$

where $f$ is mole fraction of $\gamma^{\prime}$ phase. Seeing microstructure, $\gamma$ phase of composition A and $\gamma^{\prime}$ phase of composition B are intermingled with the ratio $(1-f): f$ and the chemical potential of alloying element $i$ is expressed as

$$
\mu_{i}^{\mathrm{A}(\gamma)}=\mu_{i}^{\mathrm{B}\left(\gamma^{\prime}\right)}=\mu_{i}^{\mathrm{C}\left(\gamma+\gamma^{\prime}\right)}
$$

Substrate $\mathrm{S}$ has different $f$ but same structure as alloy $\mathrm{C}$, so the following equation is also given.

$$
\mu_{i}^{\mathrm{S}\left(\gamma+\gamma^{\prime}\right)}=\mu_{i}^{\mathrm{A}(\gamma)}=\mu_{i}^{\mathrm{B}\left(\gamma^{\prime}\right)}=\mu_{i}^{\mathrm{C}\left(\gamma+\gamma^{\prime}\right)} .
$$

From this equation, it is obtained that alloys A, B and C are in equilibrium with substrate $\mathrm{S}$ and there is no driving force of interdiffusion because the difference of the chemical potential of element $i$ is zero between substrate $\mathrm{S}$ and alloys $\mathrm{A}, \mathrm{B}$ and $\mathrm{C}$. In other words, using alloys $\mathrm{A}, \mathrm{B}$ and $\mathrm{C}$ as bond coat, SRZ formation due to the interdiffusion of alloying elements is expected to be suppressed. In this study, this concept of EQ coating is investigated and oxidation resistance of EQ coating is evaluated.

$2^{\text {nd }}$ generation Ni-base single-crystal superalloy TMS-82+ [15] and $5^{\text {th }}$ generation Ni-base single-crystal superalloy TMS-173 [16] were used as substrates. The compositions of $\gamma$ phase and $\gamma^{\prime}$ phase at $1100{ }^{\circ} \mathrm{C}$ were calculated by Alloy Design Program [17] and these compositions were used for coating materials. Compositions of samples used in this study are shown in Table I.

\section{$\beta$ Phase EQ Coating}

$\beta$ phase in Ni-base superalloys has BCC structure and generally contains large amount of $\mathrm{Al}$ and $\mathrm{Cr}$. Consequently, formation of

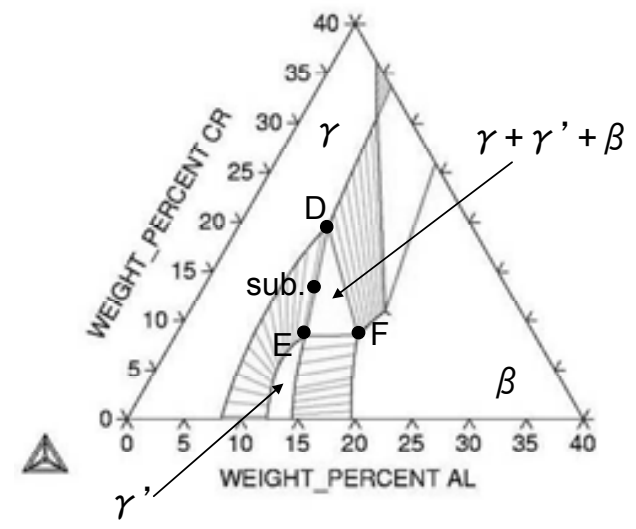

Figure 2. Ni-Al-Cr ternary phase diagram at $1100^{\circ} \mathrm{C}$.
$\mathrm{Al}_{2} \mathrm{O}_{3}$ protective scale and improvement of oxidation resistance compared with $\gamma / \gamma$ ' EQ coatings is expected. Figure 2 illustrates phase diagram of Ni-Al-Cr ternary system at $1100{ }^{\circ} \mathrm{C}$. In the region of $\gamma+\gamma^{\prime}+\beta$ equilibrium state (triangle DEF), the following equation

$$
\mu_{i}^{\mathrm{D}(\gamma)}=\mu_{i}^{\mathrm{E}\left(\gamma^{\prime}\right)}=\mu_{i}^{\mathrm{F}(\beta)}
$$

is given. If a substrate is located on $\gamma / \gamma^{\prime}$ tie-line DE, then this substrate consists of $\gamma$ phase at point $\mathrm{D}$ and $\gamma^{\prime}$ phase at point $\mathrm{E}$. Thus, the following is obtained.

$$
\mu_{i}^{\text {substrate }\left(\gamma+\gamma^{\prime}\right)}=\mu_{i}^{\mathrm{D}(\gamma)}=\mu_{i}^{\mathrm{E}\left(\gamma^{\prime}\right)}=\mu_{i}^{\mathrm{F}(\beta)} .
$$

From this equation, it is concluded that using $\beta$ phase coating on point $\mathrm{F}$ against $\gamma / \gamma$ ' substrate on line $\mathrm{DE}$, the interdiffusion at the interface of substrate and coating is suppressed in theory. Moreover, mixed phase of $\gamma, \gamma^{\prime}$ and $\beta$ for example $\beta+\gamma^{\prime}$ or $\beta+\gamma^{\prime}+\gamma$ are able to be used as coating if they are in equilibrium state, so the design of the coating is possible considering not only the oxidation resistance but also the mechanical properties. However, in the conventional $\mathrm{Ni}$-base superalloys, alloy in equilibrium state with $\beta$ phase does not exist. In this study, Ni-base superalloy in equilibrium with $\beta$ phase is developed and the possibility of $\beta$ phase as EQ coating is investigated.

Compositions of the substrates and coating materials were determined by using thermodynamic calculation software, Thermo-Calc Software (Thermo-Calc Software, Sweden). $\gamma+\gamma^{\prime}+\beta$ three-phase equilibrium composition at $1100{ }^{\circ} \mathrm{C}$ were calculated for Ni-Al-Co-Cr-Hf-Mo-Ta-W system. Substrates were designed as consisting of $\gamma$ phase and $\gamma^{\prime}$ phase with mole ration of 0.5 and the compositions of coating materials were determined as the compositions of $\beta$ single phase. Nominal compositions of the substrate alloys and coating alloys used as samples are shown in Table I.

\section{Experimental Procedure}

Concept of EQ coating was confirmed in the diffusion couple experiment. Equilibrium compositions of $\gamma, \gamma^{\prime}$ and $\beta$ phase of each substrates were calculated by using Alloy Design Program [17] developed in NIMS and Thermo-Calc software (Thermo-Calc Software, Sweden) for the temperature of $1100^{\circ} \mathrm{C}$. Following the composition shown in Table I, samples of coating materials were arc melted. After homogenization, each sample was cut into $10 \mathrm{~mm}$ in diameter and $5 \mathrm{~mm}$ in thickness. Sample surfaces were polished by $0.05 \mu \mathrm{m}-\varphi \mathrm{Al}_{2} \mathrm{O}_{3}$ particles into mirror surface and cleaned. After cleaning, coating materials were coupled with the single-crystal superalloy substrates. Diffusion couples of substrate alloy and coating alloy were bonded by pressing against each other using ceramic holder and heated at $1100{ }^{\circ} \mathrm{C}$ for $1 \mathrm{~h}$ in 
Table II. Nominal Compositions of Modified EQ Coatings. (wt\%, Ni bal.)

\begin{tabular}{|c|c|c|c|c|c|c|c|c|c|c|c|c|}
\hline Sample & $\mathrm{Co}$ & $\mathrm{Cr}$ & Mo & $\mathrm{W}$ & $\mathrm{Al}$ & $\mathrm{Ti}$ & $\mathrm{Ta}$ & Hf & $\operatorname{Re}$ & $\mathrm{Ru}$ & $\mathrm{Si}$ & $\mathrm{Y}$ \\
\hline TMS82+ $\gamma^{\prime}$ & 4.7 & 1.4 & 0.9 & 7.2 & 7.9 & 0.7 & 9.5 & 0.2 & 0.5 & - & - & - \\
\hline TMS- $82+\gamma^{\prime}+0.5 \mathrm{Si}$ & 4.7 & 1.4 & 0.9 & 7.2 & 7.9 & 0.7 & 9.5 & 0.2 & 0.5 & - & 0.5 & - \\
\hline TMS- $82+\gamma^{\prime}+0.1 \mathrm{Si}$ & 4.7 & 1.4 & 0.9 & 7.2 & 7.9 & 0.7 & 9.5 & 0.2 & 0.5 & - & 0.1 & - \\
\hline TMS- $82+\gamma^{\prime}+0.1 \mathrm{Y}$ & 4.7 & 1.4 & 0.9 & 7.2 & 7.9 & 0.7 & 9.5 & 0.2 & 0.5 & - & - & 0.1 \\
\hline TMBC-1 & 6.2 & 4.0 & 1.0 & 4.5 & 8.1 & - & 9.9 & 0.4 & - & - & - & 0.1 \\
\hline TMS-173 $\gamma^{\prime}$ & 4.2 & 1.5 & 1.5 & 5.3 & 7.8 & - & 8.0 & 0.2 & 2.6 & 3.9 & - & - \\
\hline TMS- $173 \gamma^{\prime}+0.5 \mathrm{Si}$ & 4.2 & 1.5 & 1.5 & 5.3 & 7.8 & - & 8.0 & 0.2 & 2.6 & 3.9 & 0.5 & - \\
\hline TMS-173 $\gamma^{\prime}+0.1 \mathrm{Si}$ & 4.2 & 1.5 & 1.5 & 5.3 & 7.8 & - & 8.0 & 0.2 & 2.6 & 3.9 & 0.1 & - \\
\hline TMS-173 $\gamma^{\prime}+0.5 Y$ & 4.2 & 1.5 & 1.5 & 5.3 & 7.8 & - & 8.0 & 0.2 & 2.6 & 3.9 & - & 0.5 \\
\hline TMS- $173 \gamma^{\prime}+0.1 \mathrm{Y}$ & 4.2 & 1.5 & 1.5 & 5.3 & 7.8 & - & 8.0 & 0.2 & 2.6 & 3.9 & - & 0.1 \\
\hline TMS- $173 \gamma^{\prime}+0.5 \mathrm{Hf}$ & 3.9 & 1.2 & 1.8 & 5.5 & 7.8 & - & 7.9 & 0.7 & 1.8 & 3.4 & - & - \\
\hline TMS- $173 \gamma^{\prime}+0.1 \mathrm{Hf}$ & 3.9 & 1.2 & 1.8 & 5.5 & 7.8 & - & 7.9 & 0.3 & 1.8 & 3.4 & - & - \\
\hline
\end{tabular}

vacuum furnace. Then the couples were heated at $1100{ }^{\circ} \mathrm{C}$ for 300 $\mathrm{h}-1000 \mathrm{~h}$ in air. Oxidation resistances of coating materials were examined by $1 \mathrm{~h}$ cyclic oxidation examination at $1100{ }^{\circ} \mathrm{C}$ in air. Cross sections of each diffusion couple were observed by Scanning Electron Microscope (SEM) and concentration profiles were analyzed by Energy Dispersive X-ray Spectroscopy (EDX) and Electron Probe Microanalyzer (EPMA). Oxides formed on the surface after the oxidation examinations were observed and oxidation mechanisms were discussed.

The oxidation resistance of EQ coating materials can be further improved without losing the concept. The modified EQ coatings for the $2^{\text {nd }}$ and $5^{\text {th }}$ generation superalloys are shown in Table II.

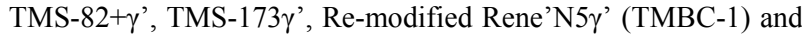
CoNiCrAlY alloy, which has same composition with commercial CoNiCrAlY coating Amdry 9954 (Sulzer Metco Ltd), were arc melted. Y, Hf and Si were added to each material to improve the oxidation resistance. Cyclic oxidation properties of the EQ specimens were examined at $1100{ }^{\circ} \mathrm{C}$ and $1150{ }^{\circ} \mathrm{C}$. Modified EQ coatings were coupled with various substrates and heat treated at $1100{ }^{\circ} \mathrm{C}$ for $300 \mathrm{~h}$. Thickness of the diffusion zone and SRZ were evaluated for these diffusion couples by using SEM and EDX.

Composition of EQ coating TMBC-1 (Rene'N5 $\gamma^{\prime}-\mathrm{Re}+\mathrm{Y}$ ) designed for 2 nd generation superalloy Rene'N5 was used as that of spray powder for High Velocity Frame Spray (HVOF spray). Amdry 9954 was also used for the comparison. Substrates were 4th generation Ni-base superalloys TMS-138 and TMS-138A. Nominal compositions of coatings and substrates are shown in Table III. TMBC-1 is designed as $\gamma$ ' phase of Rene'N5 and Re was removed, so improvement of the oxidation resistance and reduction of the material cost are able to expected in this coating.
$100 \mu \mathrm{m}$-thick of EQ and Amdry9954 coating were applied to TMS-138 and TMS-138A by HVOF. Samples were heat treated at $1100^{\circ} \mathrm{C}$ for $300 \mathrm{~h}$ in air. After heat treatment, cross sections of samples were observed by SEM and compositions of phases precipitated at the interface were analyzed by EDX.

High temperature creep properties of 4 th generation single crystal superalloy TMS-138 with various coating were investigated. Plate test pieces of TMS- 138 with $3 \mathrm{~mm}$ of width were used. The thicknesses of specimens were varied from $1 \mathrm{~mm}$ to $4 \mathrm{~mm}$. Tensile axis of specimens were within $10^{\circ}$ from $<100>$ orientation. EQ coating TMBC-1 and conventional coating Amdry9954 were applied to the surface of plate test pieces by HVOF. Al-diffusion coating and Pt-Al coating were also applied by following procedure. Aluminum halide was reduced on the surface of specimen at the temperature same as primary ageing temperature. Aluminum was diffused into the substrate and $\beta$-NiAl layer was formed at whole surface. Samples were partly platinum-plated before Al-diffusion process and Pt-Al coating was formed. These $\mathrm{Al}$ and Pt-Al diffusion coated samples were secondary aged and used for the creep test. Creep test were conducted at $1100 \mathrm{C}$ with $137 \mathrm{MPa}$.

\section{Results and Discussion}

Cross sections of diffusion couples of TMS-82+ and coating materials (a) TMS- $82+\gamma$ and (b) TMS- $82+\gamma$ ' after diffusion at $1100{ }^{\circ} \mathrm{C}$ for $300 \mathrm{~h}$ are shown in Figure 3. In both diffusion couples, SRZ was not found and very thin diffusion layers were only observed. In $\gamma^{\prime}$ phase alloy, little amount of disk-like TCP phase was found but these particles disperse uniformly throughout the whole sample and it is estimated that the reason of this TCP

Table III. Nominal Compositions of Substrates and HVOF Sprayed Coatings. (wt\%, Ni bal.)

\begin{tabular}{|l|rrrrrrrrrr|}
\hline Sample & Co & Cr & Mo & W & Al & Ta & Hf & Re & Ru & Y \\
\hline TMS-138 & 5.9 & 2.9 & 2.9 & 5.9 & 5.9 & 5.9 & 0.1 & 4.9 & 2.0 & - \\
TMS-138A & 5.8 & 3.2 & 2.8 & 5.6 & 5.7 & 5.6 & 0.1 & 5.8 & 3.6 & - \\
\hline TMBC-1 & 6.2 & 4.0 & 1.0 & 4.5 & 8.1 & 9.9 & 0.4 & - & - & 0.1 \\
Amdry9954 & 38.5 & 21.0 & - & - & 8.0 & - & - & - & - & 0.5 \\
\hline
\end{tabular}



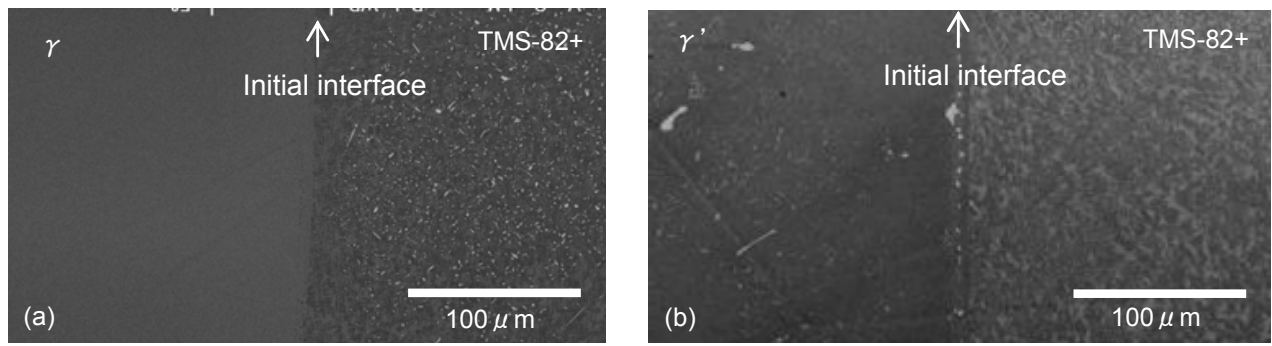

Figure 3. Cross sections of diffusion couples of (a) $\gamma$-EQ coating and (b) $\gamma$ '-EQ coating with TMS-82+ substrate heated at $1100{ }^{\circ} \mathrm{C}$ for $300 \mathrm{~h}$.

formation is not due to the diffusion but heat treatment condition. From the concentration profile analysis of $\mathrm{Al}$ and $\mathrm{Co}$ in TMS$82+\gamma /$ TMS- $82+$ and TMS- $82+\gamma^{\prime} /$ TMS- $82+$ diffusion couples analyzed by using EPMA, the thicknesses of diffusion layers were evaluated as $5 \mu \mathrm{m}$ and $15 \mu \mathrm{m}$, respectively. In the conventional coating system, TMS-82+ is reported to form over $100 \mu \mathrm{m}$ of the diffusion layer with NiCrAlY coating [11]. From these results, using $\gamma$ and $\gamma^{\prime}$ phase of TMS-82+ as coating of TMS-82+ substrate, it is concluded that the thickness of the diffusion layer between the coating and the substrate will be suppressed drastically.

Results of the cyclic oxidation examination performed to optimize the EQ coatings in $\gamma / \gamma^{\prime}$ tie-line alloys are shown in Figure 4 . The examination was performed at $1100{ }^{\circ} \mathrm{C}$ in air, using TMS-82+, TMS- $82+\gamma$ and TMS- $82+\gamma$ '. It is clarified from this result that alloys of TMS-82 $+\gamma$ shows largest mass increase in the first few cycles and decrease in the following cycles due to fast oxidation and spallation. TMS- $82+\gamma$ ' shows most excellent oxidation resistance in 50 cycles' examination and it is obviously improved from that of TMS-82+. Difference of the oxidation property of $\gamma$ phase and $\gamma^{\prime}$ phase is due to the structure of oxide. While $\gamma^{\prime}$ phase forms protective $\mathrm{Al}_{2} \mathrm{O}_{3}$ layer, $\gamma$ phase mainly forms non-protective thick $\mathrm{NiO}$ and particles of $\mathrm{Al}_{2} \mathrm{O}_{3}$ inner oxide. Thus, it is concluded that $\gamma^{\prime}$ phase is promising material for oxidation-resistant coating.

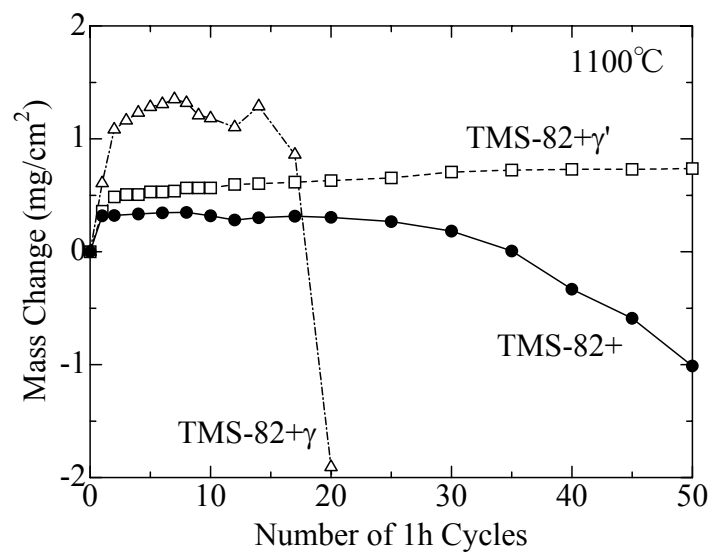

Figure 4. Cyclic oxidation properties of TMS-82+ tie-line alloys at $1100^{\circ} \mathrm{C}$.

The effect of $\gamma^{\prime}$ EQ coating on $5^{\text {th }}$ generation superalloy was also investigated using the diffusion couple of $5^{\text {th }}$ generation superalloy TMS-173 and its $\gamma^{\prime}$ phase. As shown in Figure 5, diffusion layer of $2 \mu \mathrm{m}$ thick was obtained after the diffusion at $1100{ }^{\circ} \mathrm{C}$ for $1000 \mathrm{~h}$. Thus, it is confirmed that the concept of EQ coating is able to be applied to $\mathrm{Ru}$-containing $5^{\text {th }}$ generation $\mathrm{Ni}$ base superalloy.

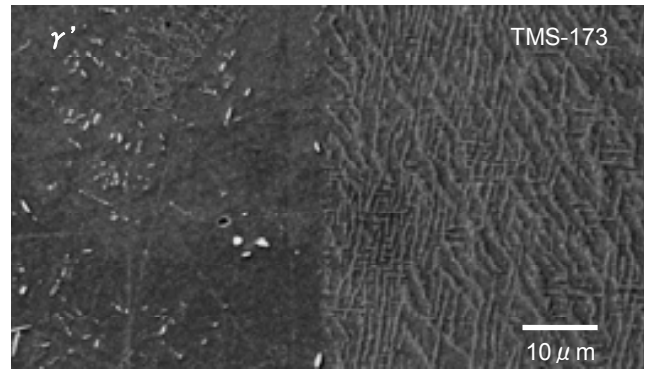

Figure 5. Cross section of TMS-173 $\gamma^{\prime} /$ TMS-173 diffusion couple diffused at $1100{ }^{\circ} \mathrm{C}$ for $1000 \mathrm{~h}$.

The idea of EQ coating is now developed into $\beta$ phase coating. A single crystal of Ni-Al-Co-Cr-Hf-Mo-Ta-W system superalloy TMS-209 and its $\beta$ phase alloy were designed as they are in equilibrium. TMS-209, $\gamma / \gamma^{\prime}$ substrate was cast in DS furnace and solution heat treated at $1280{ }^{\circ} \mathrm{C}$ for $5 \mathrm{~h}$. Primary aged at $1100{ }^{\circ} \mathrm{C}$ for $4 \mathrm{~h}$ and secondary aged at $870{ }^{\circ} \mathrm{C}$ for $20 \mathrm{~h}$. This alloy has almost same creep strength as $1^{\text {st }}$ generation superalloy CMSX-2 [14]. TMS-209 $\beta$ was arc melted. Diffusion couple of TMS209/TMS-209 $\beta$ system was heat treated at $1100{ }^{\circ} \mathrm{C}$ for $460 \mathrm{~h}$ and cross section observation was conducted as shown in Figure 6. Although the composition of arc-melted material was not accurate as the equilibrium state, the diffusion zone at the interface was minimized as only $10 \mu \mathrm{m}$. From this result, it is confirmed that the concept of EQ coating is possible to be applied to $\beta$ phase coating and Ni-base superalloy in equilibrium with $\beta$ phase.

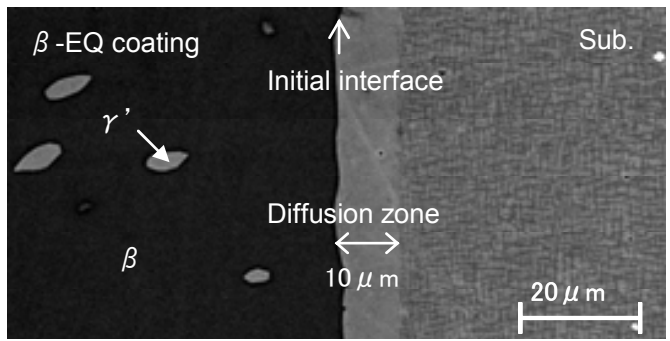

Figure 6. Cross section of $\beta$-EQ coating/1st generation superalloy TMS-209 heated at $1100^{\circ} \mathrm{C}$ for $460 \mathrm{~h}$. 
Figure 7 shows cyclic oxidation properties of EQ coatings for $2^{\text {nd }}$ generation superalloys TMS- $82+$ and Rene' $\mathrm{N} 5$ at $1100^{\circ} \mathrm{C} .0 .5 \mathrm{wt} \%$ of $\mathrm{Si}$ addition to TMS-82+ increase mass gain due to the accelerated oxidation but $0.1 \mathrm{wt} \%$ of $\mathrm{Si}$ and $0.1 \mathrm{wt} \%$ of $\mathrm{Y}$ make oxidation rate slower. Re-removed and Y-added Rene'N5 $\gamma$ '
(TMBC-1) shows better oxidation resistance than modified TMS$82+\gamma$ ' because of its high $\mathrm{Al}$ and $\mathrm{Cr}$ content. An experiment to improve the oxidation resistance of $\gamma^{\prime}$-EQ coating for $5^{\text {th }}$ generation superalloy TMS-173 was also attempted. Results of Hf, $\mathrm{Si}$ and $\mathrm{Y}$ addition are shown in Figure 8. Mass change of TMS$173 \gamma$ ' showed decrease due to the spallation. Hf, Si and Y

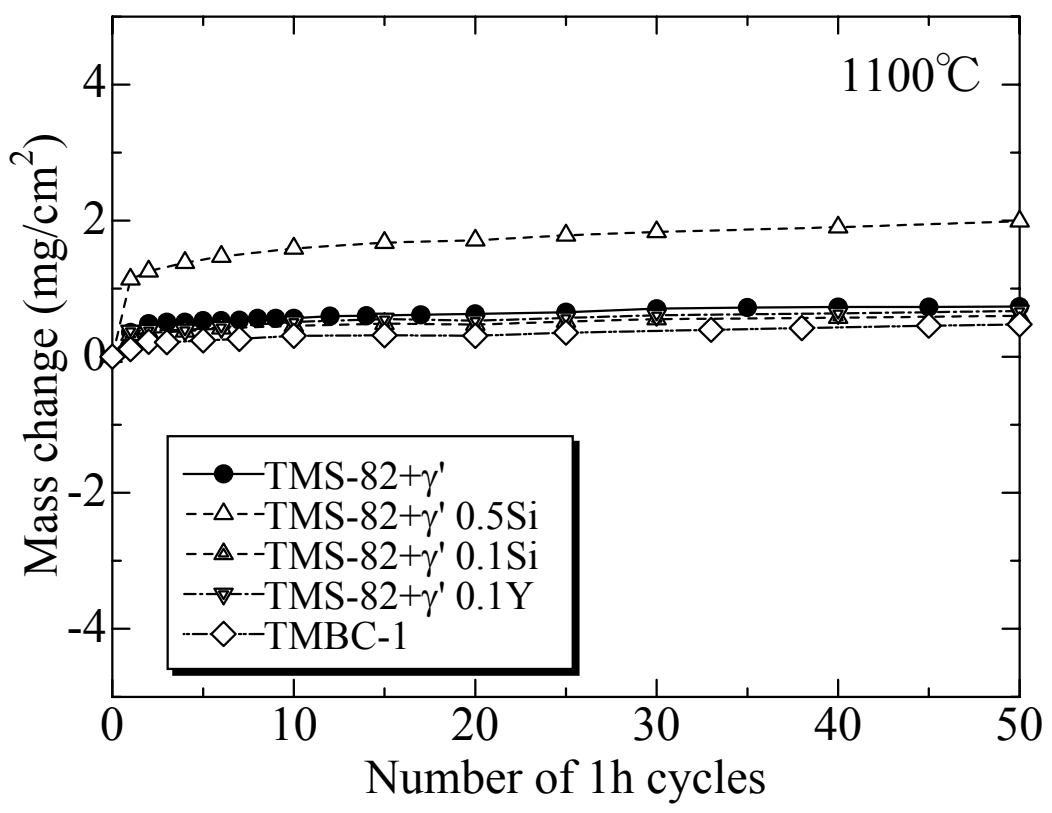

Figure 7. Cyclic oxidation properties of EQ coatings for 2nd generation superalloys.

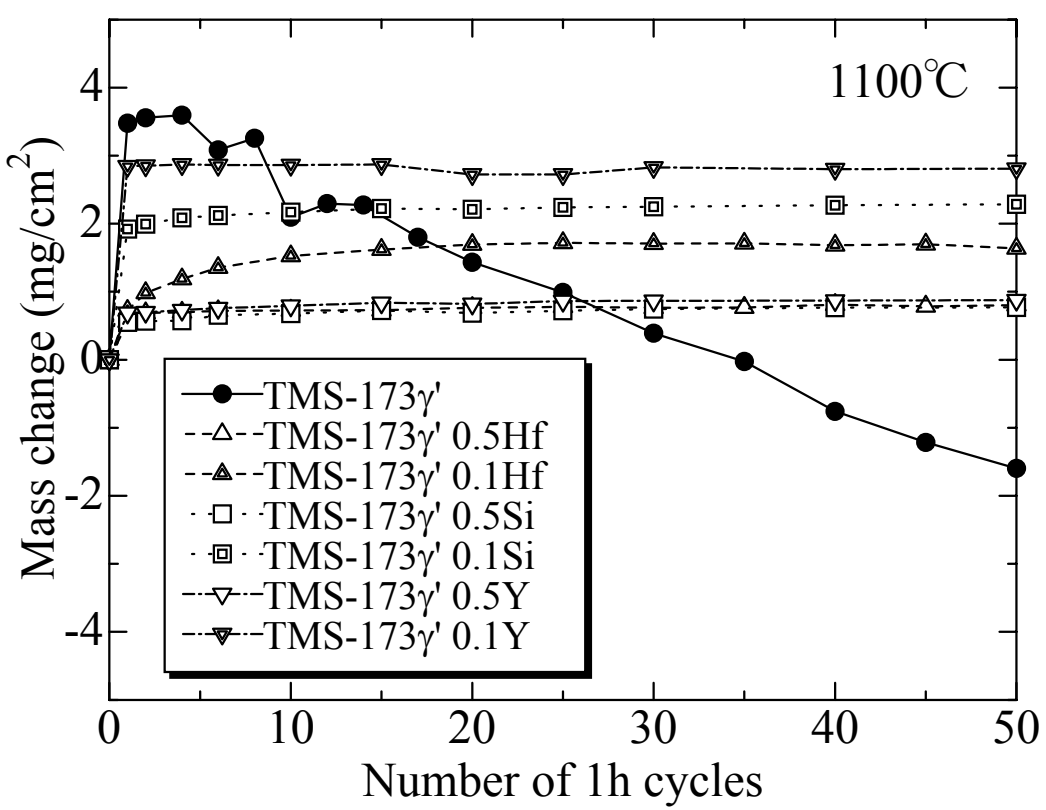

Figure 8. Improvement of oxidation resistance of EQ coating of 5th generation superalloy. 


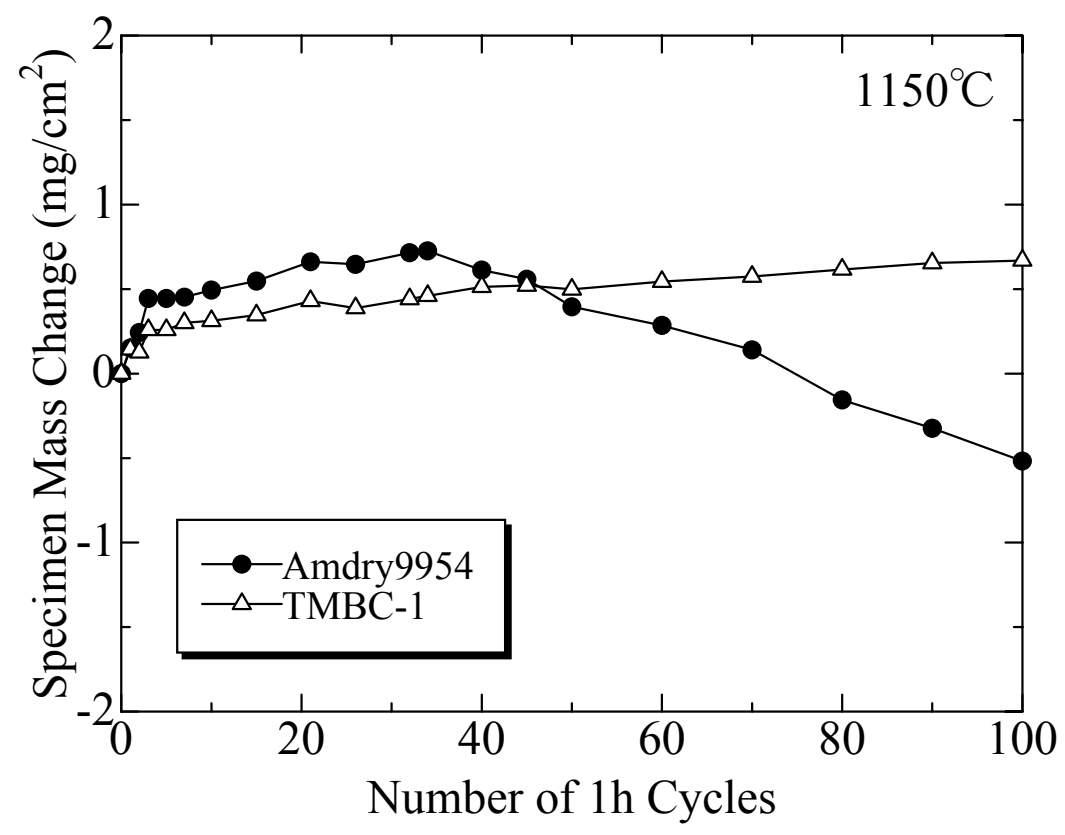

Figure 9. Cyclic oxidation properties of EQ coatings and CoNiCrAlY coating at $1150^{\circ} \mathrm{C}$.

addition improved the adhesiveness of the scale and the spallation was suppressed. $0.1 \mathrm{wt} \%$ of Y showed higher mass increase than $0.1 \mathrm{wt} \%$ of $\mathrm{Si}$ and $\mathrm{Hf}$, and $0.5 \mathrm{wt} \%$ of $\mathrm{Y}, \mathrm{Si}$ and $\mathrm{Hf}$ addition improved the oxidation resistance. $0.5 \mathrm{wt} \%$ of $\mathrm{Hf}$ addition indicates the best oxidation property. These additions of trace element were found not to affect the interdiffusion in cross section observation of the diffusion couple experiments.

Cyclic oxidation resistance of TMBC-1 (Rene'N5 $\gamma^{\prime}-\mathrm{Re}+\mathrm{Y}$ ) and Amdry 9954 at $1150{ }^{\circ} \mathrm{C}$ were evaluated and shown in Figure 9, using arc-melted specimens. TMBC-1 shows small mass increase at early cycles and gradual increase in mass change although mass change of Amdry9954 increases markedly at early cycles and decreases due to spallation of the scale from 40 cycle onward. This result proves clearly that the cyclic oxidation resistance of developed EQ coating is superior to that of the conventional CoNiCrAlY coating.

TMBC-1 was deposited to various superalloys by HVOF spray to confirm practical advantage. Figure 10 displays cross sections of (a) conventional CoNiCrAlY coating and (c) TMBC-1 EQ coating HVOF deposited on TMS-138A after heat treated at $1100^{\circ} \mathrm{C}$ for $300 \mathrm{~h}$. In the conventional coating system, about $90 \mu \mathrm{m}$ of primary diffusion zone and $140 \mu \mathrm{m}$ of SRZ are observed at the interface as a matter of course. However, although TMBC-1 is not equilibrium phase with TMS-138A, this coating system proved that SRZ
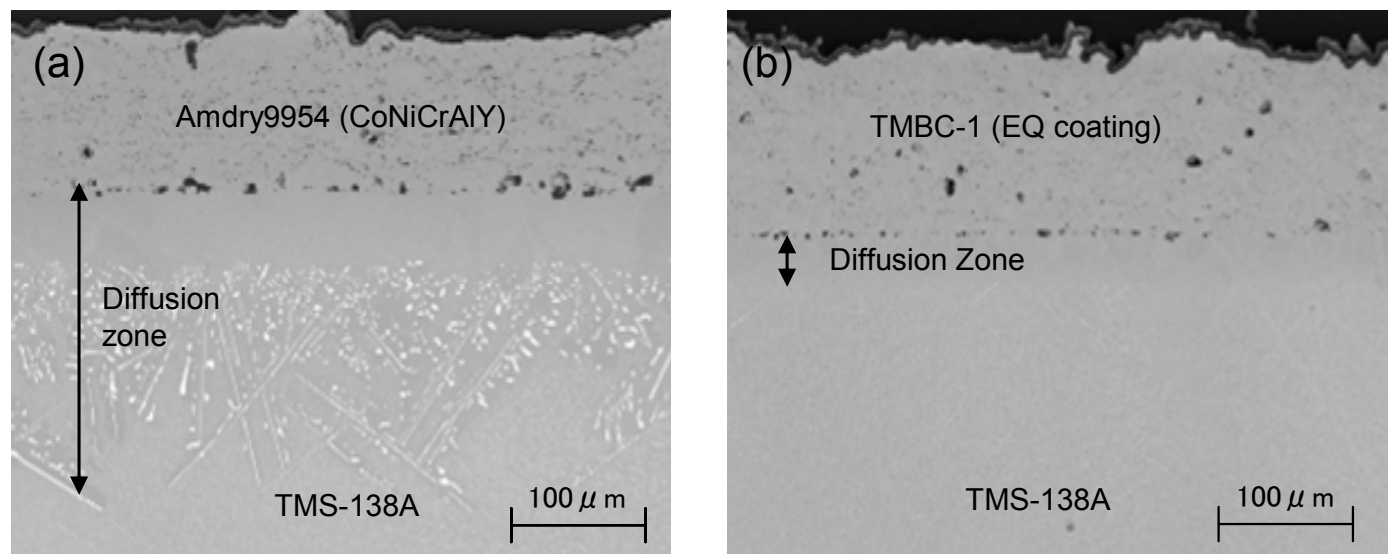

Figure 10. Cross section of HVOF sprayed (a) CoNiCrAlY and (b) EQ coating on TMS-138A substrate exposed to $1100^{\circ} \mathrm{C}$ for $300 \mathrm{~h}$. 
formation is completely suppressed and diffusion layer is small enough to tolerate. This result means that Re modification and $\mathrm{Y}$ addition do not affect to the diffusion behavior and EQ coating is able to apply widely to several superalloys if the chemical potentials of the alloying elements for coating and substrate are close enough and consequently material and process cost will be reduced.

Figure 11 shows Creep properties of $4^{\text {th }}$ generation superalloy TMS-138 with various coatings investigated at $1100{ }^{\circ} \mathrm{C}$ with $137 \mathrm{MPa}$. Plate test pieces were used and specimen thicknesses were varied from $1 \mathrm{~mm}$ to $4 \mathrm{~mm}$. Without coating, bare materials showed constant strength regardless of the thickness. Aluminized, Pt-Aluminized and HVOF CoNiCrAlY coating showed the decrease of Larson-Miller Parameter (LMP) with the thickness decreasing. This is due to the increase of SRZ effect on the total cross section of the specimen. Ratio of SRZ area against the total cross section becomes larger in the thinner specimen, and as a result, the load bearing cross section is reduced. However, EQ coating does not form SRZ and it does not degrade the creep strength, so this coating showed almost similar LMP to bare TMS-138 in thinnest specimen. It follows from what has been said that EQ coating is a hopeful technique to keep the mechanical strength of superalloy during high temperature exposure. Thus, it is concluded that EQ coating is a new and practical low-cost technique to suppress the SRZ formation without using Pt.

It is found that EQ coating is widely available to advanced generation Ni-base superalloys not degrading the high temperature strength by using equilibrium compositions. $3^{\text {rd }}$ and more advanced generation Ni-base superalloys contain high amount of Re and SRZ formation is not avoidable. Recently, thickness of high pressure turbine blade is getting thinner and thinner for the improvement of cooling efficiency and decrease of engine weight and so this problem has been serious. EQ coating will be a new low-cost technique to solve this problem. And this technique has a benefit in a repairing process of the turbine blades. Usually, only one-time re-coating is possible in reuse of the turbine blades, because coating layer and the diffusion layer beneath the coating have to be removed before re-coating and the thickness of sound substrate become thinner. However, it is not necessary to remove a thick diffusion layer in EQ coating system because it suppresses SRZ formation. EQ coating makes possible cyclic re-coating and consequently will make a great contribution to airlines in their cost performance of engine maintenance. It should be reasonably concluded that EQ coating is extremely hopeful and innovative technique for the practical use of the advanced Ni-base superalloys.

\section{Conclusions}

The concept of SRZ-resistant EQ coating was confirmed in the diffusion couple experiments. The oxidation resistance of EQ coating for the $2^{\text {nd }}$ generation superalloy has been improved by $\mathrm{Si}$ and $\mathrm{Y}$ addition, and its application is extended to the $4^{\text {th }}$ generation superalloy. EQ coating for the $5^{\text {th }}$ generation superalloy has also been developed and the possibility of the improvement of the oxidation resistance was investigated. Creep test at $1100{ }^{\circ} \mathrm{C} / 137 \mathrm{MPa}$ proved that EQ coating does not degrade the mechanical strength in long time high temperature exposure because of its structural stability.

\section{Acknowledgements}

The authors would like to express their sincere thanks to Dr. T. Kobayashi of NIMS for his single-crystal making, to Dr. E.

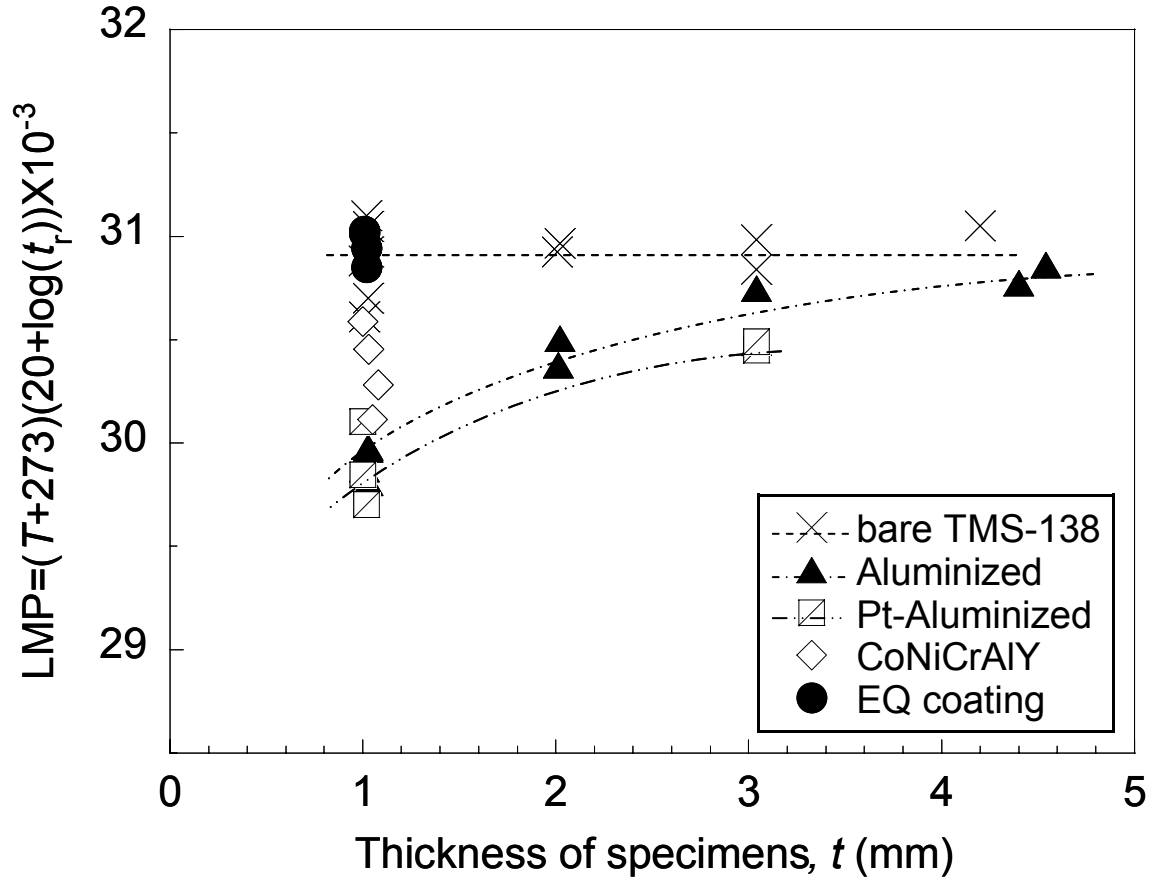

Figure 11. Larson-Miller Parameter distribution with various thicknesses of creep specimens for bare and coated TMS-138. 
Bannai of NIMS for his operations of arc-melting, and to Dr. Y. Aoki and Mr. M. Arai of IHI Corporation for their conducting creep test and invaluable suggestions. This research was supported in part by a Grant-in-Aid for Scientific Research (18760538) from Japan Society for the Promotion of Science (JSPS).

\section{References}

1. J. X. Zhang, T. Murakumo, Y. Koizumi, T. Kobayashi, H. Harada and S. Masaki Jr., "Interfacial Dislocation Networks Strengthening a Fourth-Generation Single-Crystal TMS-138 Superalloy", Metall. Mater. Trans. A, 33, (12) (2002), 37413746 .

2. S. Walston, A. Cetel, R. MacKay, K. O’ Hara, D. Duhl and R. Dreshfield, "Joint Development of a Fourth Generation Single Crystal Superalloy", Superalloys 2004 (2004), 15-24.

3. W. S. Walston, J. C. Schaeffer and W. H. Murphy, "A New Type of Microstructural Instability in Superalloys - SRZ", Superalloy 1996, (TMS, 1996) 9-18.

4. Y. Matsuoka, Y. Aoki, K. Matsumoto, A. Sato, T. Suzuki, K. Chikugo and K. Murakami, "The Formation of SRZ on a Fourth Generation Single Crystal Superalloy Applied with Aluminide Coating”, Superalloy 2004 (2004), 637-642.

5. I. E. Locci, R. A. Mackay, A. Grag and F. J. Ritzert, "Successful Surface Treatments for Reducing Instabilities in Advanced Nickel-Base Superalloys for Turbine Blades", NASA/TM-2004-212920, March (2004).

6. O. Lavigne, C. Ramusat, S. Drawin, P. Caron, D. Boivin and J. -L. Pouchou, "Relationships Between Microstructural Instabilities and Mechanical Behavior in New Generation Nickel-Based Single Crystal Superalloys", Superalloy 2004 (2004), 667-675.

7. T. Narita, S. Hayashi, H. Yukawa, M. Noguchi and M. Miyasaka, "Alloy Coating, Method for Forming the Same, and Member for High Temperature Apparatuses", U. S. Patent 6830827 (2004).
8. I. T. Spitzberg, R. Darolia, M. R. Jackson, J. C. Zhao and J. C. Schaeffer, "Diffusion Barrier Layer", U. S. Patent 6306524 (2001).

9. R. G. Wing, "Method of Aluminising a Superalloy", U. S. Patent 6080246 (2000).

10. H. Harada, A. Sato and K. Kawagishi, Japanese Patent Pending, Tokugan 2005-092542 (2005).

11. A. Sato, H. Harada and K. Kawagishi, "Development of New Bond Coat 'EQ Coating' System", Metall. Mater. Trans. A, 37 (2) (2006), 790-791.

12. A. Sato, H. Harada and K. Kawagishi, "Development of New Bond Coat System in Ni-base Alloys", Materials Science Forum, 522-523, (2006) 361-368.

13. K. Kawagishi, A. Sato and H. Harada, "Development of Oxidation-Resistant $\beta$-phase EQ Coating System for NiBase Superalloys", J. Japan Inst. Metals, 70 (2) (2006) 188191.

14. K. Kawagishi, A. Sato, T. Kobayashi and H. Harada, "Oxidation and Creep Properties of Ni-base Single crystal Superalloy for $\beta$-phase EQ Coating System", J. Japan Inst. Metals, 70 (8) (2006), 690-693.

15. T. Hino, T. Kobayashi, Y. Koizumi, H. Harada and T. Yamagata, "Development of a New Single Crystal Superalloy for Industrial Gas Turbines", Superalloy 2000 (2000), 729-736.

16. Y. Koizumi, T. Kobayashi, T. Yokokawa, Z. Jianxin, M. Osawa, H. Harada, Y. Aoki and M. Arai, "Development of Next-Generation Ni-Base Single Crystal Superalloys", Superalloys 2004 (2004), 35-43.

17. H. Harada, K. Ohno, T. Yamagata, T. Yokokawa and M. Yamazaki, "Phase Calculation and Its Use in Alloy Design Program for Nickel-Base Superalloys", Superalloys 1988 (1988), 733-742. 